Sādhanā Vol. 40, Part 6, September 2015, pp. 1845-1863. (C) Indian Academy of Sciences

\title{
Computational heat transfer analysis and combined ANN-GA optimization of hollow cylindrical pin fin on a vertical base plate
}

\author{
C BALACHANDAR, S ARUNKUMAR and M VENKATESAN* \\ School of Mechanical Engineering, SASTRA University, Tirumalaisamudram, \\ Thanjavur 613 401, Tamilnadu, India \\ e-mail: mvenkat@mech.sastra.edu
}

MS received 9 May 2014; revised 2 September 2014; accepted 14 February 2015

\begin{abstract}
In the devices like laptops, microprocessors, the electric circuits generate heat while performing work which necessitates the use of fins. In the present work, the heat transfer characteristics of hollow cylindrical pin fin array on a vertical rectangular base plate is studied using commercial CFD code ANSYS FLUENT C. The hollow cylindrical pin fins are arranged inline. The heat transfer augmentation is studied for different parameters such as inner radius, outer radius, height of the fins and number of pin fins. The base plate is supplied with a constant heat flux in the range of 20$500 \mathrm{~W}$. The base plate dimensions are kept constant. The base plate temperature is predicted using Artificial Neural Network (ANN) by training the network based on the results of numerical simulation. The trained ANN is used to analyse the fin in terms of enhanced heat transfer and weight reduction when compared to solid pin fin. Optimization of the hollow cylindrical pin fin parameters to obtain maximum heat transfer from the base plate is carried out using Genetic Algorithm (GA) applied on the trained neural network. The analysis using the numerical simulation and neural network shows that the hollow fins provide an increased heat transfer and a weight reduction of about $90 \%$ when compared to solid cylindrical pin fins.
\end{abstract}

Keywords. Hollow cylindrical pin fin; natural convection; Artificial Neural Network; Genetic Algorithm; optimization.

\section{Introduction}

Fins are protrusions on a surface used to maintain the temperature below a limiting value in order to make the system efficient. Fins of various shapes such as rectangular, cylindrical and trapezoidal geometries and other special profiles are used to enhance heat transfer from the system. Fins are used to remove heat in electronic circuits, laptops and other appliances that generate heat while performing work.

*For correspondence 
Several experimental and numerical works have been done in the past to analyse the heat transfer characteristics of fins with various shapes and profiles. Experimental investigation of natural convection heat transfer of fins of different size and orientation was done by Starner \& McManus (1963). Yuncu \& Anbar (1998) did experiment on rectangular fins in a horizontal plate and studied the heat transfer characteristics in free convection. It was concluded that heat transfer depends on parameters such as fin spacing, height and temperature difference between fin base and surroundings. Harahap \& McManus (1967) conducted experiments and studied the characteristics of natural convection heat transfer from horizontal rectangular fin arrays and found a relation between average convection coefficient and fin temperature. Sparrow \& Charmchi (1980) numerically studied the laminar heat transfer in an externally finned circular tube and proposed that heat transfer enhancement due to external fins is higher for shorter tubes and diminishes as the tube length decreases. Sparrow \& Lee (1975) investigated the effect of decrease in fin base temperature in a rectangular plate-fin array. Ledezma \& Bejan (1996) experimentally and numerically studied plate finned heat sinks in both natural and forced convection. It was concluded that overall thermal conductance of heat sink increased when the fin crests are inclined when it approached the fluid.

The advancements in embedded electronic system demands more effective fins with lesser weight compared to conventional rectangular fin. There is also a need for effective space utilization as an integrated circuit houses hundreds of electrical and electronic component in a single chip. Haldar (2010) numerically studied the natural convection over a cylindrical pin element on a horizontal plate and proposed correlations to find the base plate heat duty for a given fin diameter to length ratio. Seyf \& Layeghi (2010) numerically analysed elliptical pin fin heat sink for convective heat transfer with and without metal foams. It was concluded that the metal foams structures have significant effect on heat transfer characteristics and proposed correlations for the same. Siw et al (2012) did an experiment on pin fin array that has a partial detachment from one of the walls and found that the detachment resulted in increased turbulent transport. It was also concluded that the staggered fin array configuration resulted in an enhanced heat transfer when compared to inline configuration.

Optimization is the process of finding the most plausible and desirable solution to a problem. Optimization is also essential to obtain an economically feasible solution. Bejan \& Dan (1999) studied the constructal trees of convective fins and optimized the volume and relative thickness of the fins. It was shown that the optimized tree had minimal thermal resistance between the finite size volume and the heat source. Jones \& Smith (1970) studied the optimal arrangement of rectangular fins on horizontal surfaces for free-convection heat transfer for maximum heat transfer rate and proposed correlations to obtain optimum fin spacing. Khaled (2010) numerically studied the permissible number of fins for heat transfer enhancement and solved the energy equations numerically and found that fins with optimal number of holes to fin ratios have enhanced heat transfer than solid fins. Karvinen \& Karvinen (2010) worked in optimizing the geometry of plate fins for maximising the dissipated heat flux and proposed geometry rules for augmented heat transfer.

Several optimization techniques have been employed in many problems to get the optimal feasible solution. Sharqawy \& Zubair (2007) optimized the annular fins using an analytical approach. Liu (2005) proposed a fuzzy approach to optimize the longitudinal fin array for increased heat transfer and compared the results of regular non-fuzzy model and fuzzy model. A holistic approach for optimizing the convective fin system was studied by Sasikumar \& Balaji (2002) using genetic algorithm for optimization. Cavazzuti \& Corticelli (2008) optimized a heat exchanger using multi objective genetic algorithm. Rao \& Patel (2013) used modified teachinglearning-based optimization algorithm for optimizing heat exchangers. The main objectives in 
the work were maximising the effectiveness and minimising the cost of the heat exchanger. Yang et al (2006) optimized the fin spacing of a fin-tube heat exchanger using the Taguchi method to improve the thermal performance and the operating time of the heat exchanger. Tsai et al (2004) proposed Hybrid Taguchi-genetic algorithm for global numerical optimization. It can be seen from above literature study that soft computing techniques such as ANN, GA and Fuzzy were used extensively for the optimization of various heat transfer components. However, heat transfer analysis on hollow cylindrical pin fins is limited.

In the present study, ANN-GA based optimization technique has been used to find the fin parameters for minimum base plate temperature. Numerical simulations are performed to study the parametric dependency of the fin on base plate temperature. Since numerical study for all the parameters requires a high computing effort and time, Artificial Neural Network is applied to predict the base plate temperature of the fin. The neural network is trained by limited set of data from the simulations. ANN is able to predict the base plate temperature for various other parameters. Genetic Algorithm is applied on the trained neural network to find the optimal fin geometry for augmented heat transfer for various heat duties.

Table 1. Material properties (Yazicioglu 2005).

\begin{tabular}{lccccc}
\hline Components & Material type & $\begin{array}{c}\text { Specific } \\
\text { heat }(\mathrm{J} / \mathrm{kg} \mathrm{K})\end{array}$ & $\begin{array}{c}\text { Conductivity } \\
(\mathrm{W} / \mathrm{m} \mathrm{K})\end{array}$ & Emissivity & Roughness (mm) \\
\hline Concrete block & Aerated concrete & 1000 & 0.15 & 0.9 & 2 \\
Heater base plate & Aluminium & 900 & 130 & 0.2 & 0.02 \\
Fin array & Aluminium & 900 & 130 & 0.2 & 0.02 \\
\hline
\end{tabular}

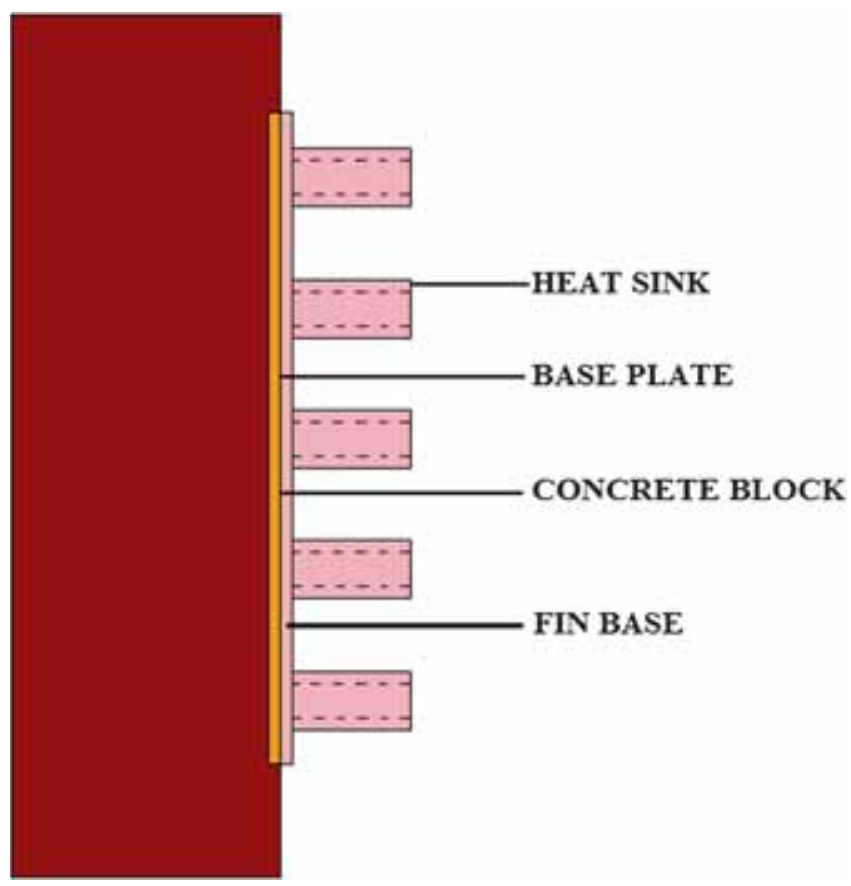

Figure 1. Side view of the model for heat sink (hollow). 


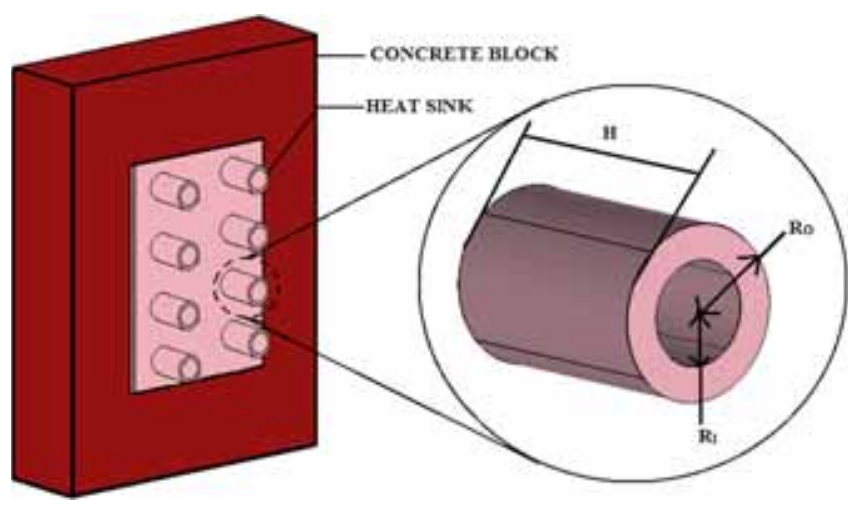

Figure 2. 3-D view of the model for heat sink (hollow).

\section{Problem description}

In present work, the cylindrical pin fins are placed perpendicular in a vertical base plate of dimensions $250 \times 180 \times 5 \mathrm{~mm}$ and the above set-up is kept over a concrete block of dimensions $340 \times 450 \times 100 \mathrm{~mm}$. The fin assembly is kept over the plate of same dimension as that of base plate. The whole assembly is kept in a closed room of dimensions $3 \times 3 \times 3 \mathrm{~m}$ with top side open and the ambient temperature is $20^{\circ} \mathrm{C}$. The material properties are specified in table 1 . The geometry taken is similar to that of experiments conducted by Yazicioglu (2005) and Yazicioglu \& Yuncu (2007) on rectangular fin array.

Figure 1 shows the side view of the modelled heat sink comprising of hollow fins. The 3D geometry of the hollow cylindrical fin is shown in figure 2. A detailed parametric study is carried out on the hollow cylindrical pin fins to determine the dependence of various parameters on the heat transfer augmentation. The parameters that are varied include inner and outer radius of fin, height of fin, number of rows and columns for different heat duties (20-500 W).

\subsection{Meshing and grid independence study}

Figures 3 and 4 represent the sectional view and 3D view of the non-conformal mesh of the cylindrical pin fin. A non-uniform meshing is applied to the model where, mesh is finer near the

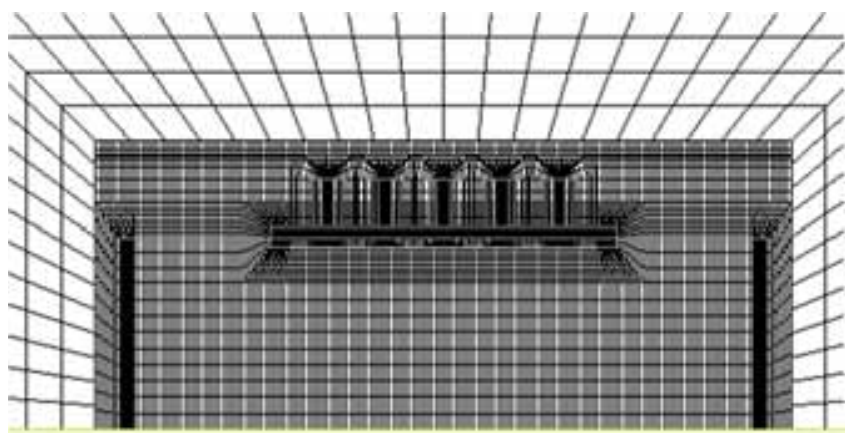

Figure 3. Sectional view of the non-conformal mesh. 


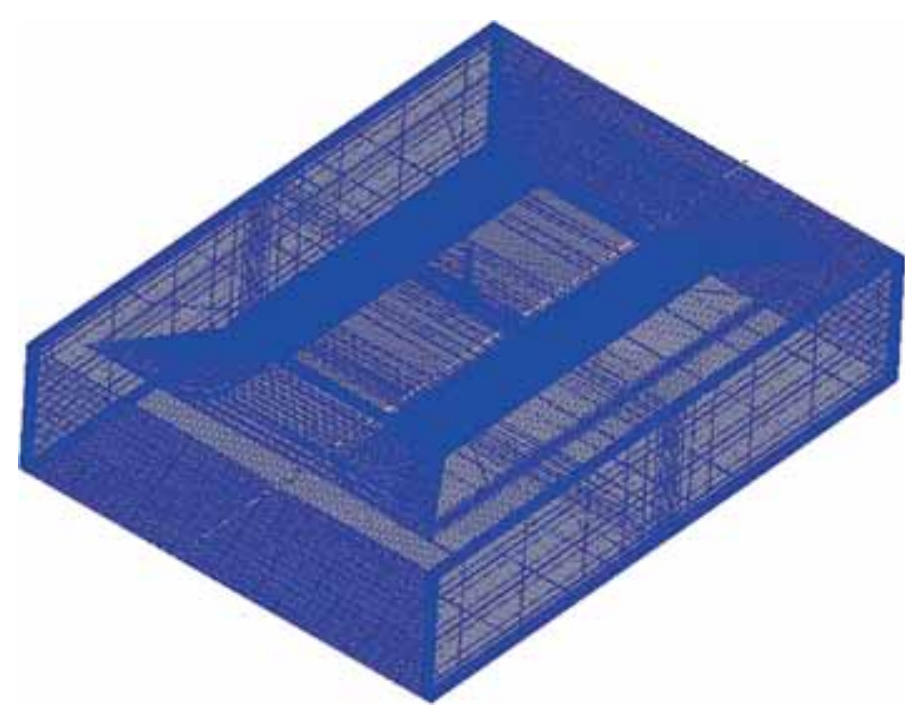

Figure 4. 3D mesh of the geometry.

fins and coarser in other places to get correct solution. Based on the grid independency study represented in figure 5 desired mesh value is reached from the number of nodes greater than 36000000. So the corresponding maximum mesh size of $0.01 \mathrm{~mm}$ is used for the entire analysis.

\subsection{Governing equations and boundary conditions}

Eqs. 1, 2 and 3 are used in numerical analysis by solving them in ANSYS FLUENT ${ }^{(}$. The continuity equation:

$$
\frac{\partial u}{\partial x}+\frac{\partial v}{\partial y}=0
$$

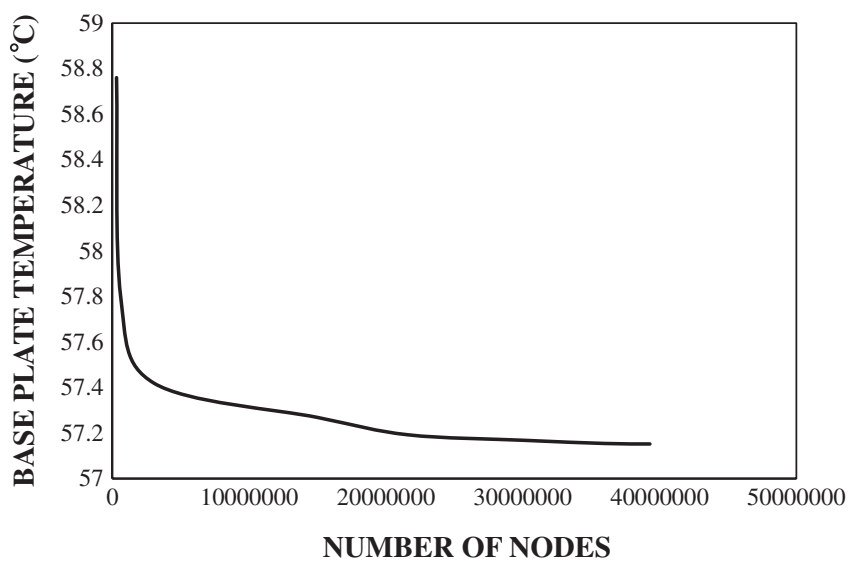

Figure 5. Grid independency study (applied on a vertical base plate supplied with $20 \mathrm{~W}$ heat supply). 
The momentum equation:

$$
u \cdot \frac{\partial v}{\partial x}+v \cdot \frac{\partial v}{\partial y}=v \cdot \frac{\partial^{2} v}{\partial x^{2}}+g \cdot \beta \cdot \Delta T .
$$

The Energy equation:

$$
g \cdot c_{p} \cdot\left(u \cdot \frac{\partial T}{\partial x}+v \cdot \frac{\partial T}{\partial x}\right)=k \cdot \frac{\partial^{2} T}{\partial x^{2}} .
$$

The boundary conditions for the analysis for the fin system are discussed below. The base plate is varied with a heat supply ranging from $20 \mathrm{~W}$ to $500 \mathrm{~W}$. The heat transfer from base plate to the fin is modelled by conduction and the heat transfer from the fin surface to the surrounding fluid takes place by convection. The variation in density of the fluid with temperature is assumed to obey Boussinesq approximation. The gravity force of magnitude $9.82 \mathrm{~m} / \mathrm{s}^{2}$ acts along the length of the base plate in the downward direction. SIMPLE pressure velocity coupling method along with second order upwind scheme for momentum and energy computation is used. Since this is a steady state problem involving a single phase flow alone, pressure based coupling method are found to be efficient when compared to normal segregated solvers. Since a wide range of geometry is tested, it is difficult to test the skewness of the mesh in all the cases. So in the numerical model SIMPLE pressure velocity coupling is used with an under relaxation factor of 0.7 . As the heat transfer and fluid flow properties vary throughout the 3 $\mathrm{D}$ space tested, the use of higher order upwind scheme is more accurate. But the third order is expected to show some dispersive error if the property gradient is high. Also the computational time increases with the increase in order of upwind scheme. So the second order upwind scheme is used to obtain an accurate solution with optimal computational time/requirements. The ratio of heat loss without considering radiation and with the heat loss considering radiation in the present case is minimal (less than $2 \%$ ) and hence heat loss is neglected in the present study.

\subsection{Numerical model and validation}

The proposed numerical set-up is initially validated with results of conventional rectangular fins available in the literature. Experimental results of Yazicioglu (2005) and Yazicioglu \& Yuncu (2007) are used for validating the numerical model. The numerical set-up is designed with thermal properties and ambient conditions same as that of the experimental one done by Yazicioglu (2005) and Yazicioglu \& Yuncu (2007). The validation is done for a solid rectangular fin kept in vertical base plate and is represented in figure 6. It shows the temperature values for a particular heat duty. The base plate temperature provided is the average base plate temperature. The modelled fin type is that of the Yazicioglu (2005) and Yazicioglu \& Yuncu (2007) with two different fin spacing(s) as mentioned in the table. Column one represents various heat duties and columns $2,3,4,5$ represent the value of temperature that is obtained numerically and experimentally. The values obtained are close to the Yazicioglu (2005) and Yazicioglu \& Yuncu (2007) values and hence the model is validated. The models are for laminar flow as the Rayleigh number is found to be less than $10^{9}$ and the model is periodically checked for laminar-turbulence transition. Analysis of fins are done on laminar flow in the present work. 


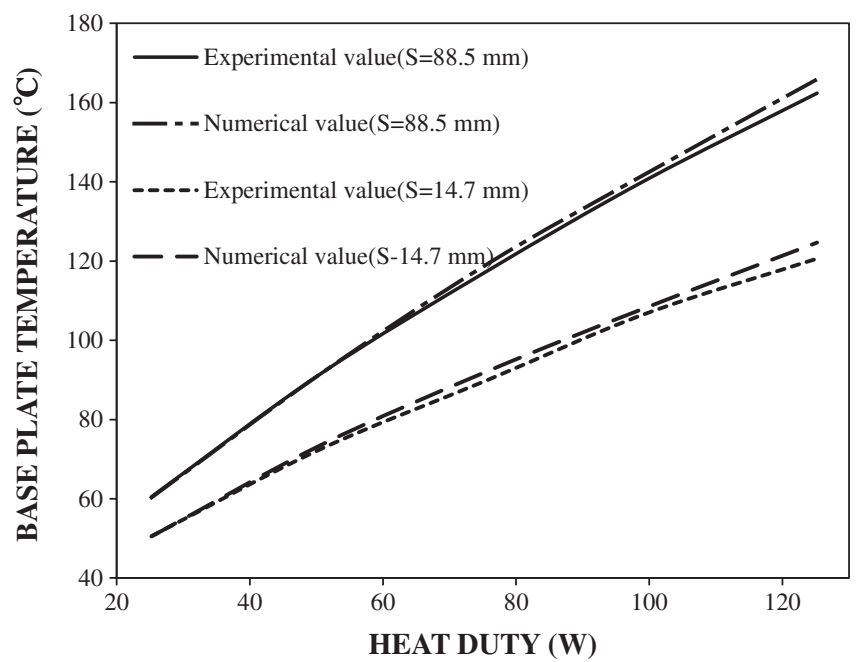

Figure 6. Validation for solid rectangular fin.

\section{Results and discussion}

\subsection{Heat transfer characteristics of hollow cylindrical fins}

In the present work, the cases for which parametric study is done is shown in table 2. It is found that the heat transfer characteristics depend on parameters like height, inner radius, outer radius, number of rows and number of columns. In case of single fin study, the location of the fin is at the centre of the base plate.

The dependence of heat transfer augmentation on the fin geometry is studied by varying its height, outer and inner radius and number of fins for a particular heat duty. In all the cases the graph is shown for $100 \mathrm{~W}$ heat supply to illustrate the effects. However, the effects are found to be similar for other heat supplies. In case 3 alone, graph for $200 \mathrm{~W}$ heat supply is also shown to describe the proliferated heat in the case of high heat flux.

3.1a Case 1 - Variation with fin height: The dependence of the heat transfer augmentation on the fin height is shown in figure 7 . The analysis was done by varying height and keeping all other parameters constant. The height of the fin is represented in the $\mathrm{X}$-axis and the base plate temperature is represented on the Y-axis. It is clear from figure 7 that the base plate temperature keep on decreasing as the height of fin is increased. The increase in heat transfer which is indicated

Table 2. Cases considered in the present analysis.

\begin{tabular}{lcc}
\hline Case no & Parameters & Range \\
\hline 1 & Height of fin $(\mathrm{H})$ & $10-45 \mathrm{~mm}$ \\
2 & Outer radius of fin $\left(\mathrm{R}_{\mathrm{O}}\right)$ & $1-15 \mathrm{~mm}$ \\
3 & Inner radius of fin $\left(\mathrm{R}_{\mathrm{I}}\right)$ & $1-\mathrm{R}_{\mathrm{O}} \mathrm{mm}$ \\
4 & Number of rows $\left(\mathrm{N}_{\mathrm{R}}\right)$ & $1-7$ \\
& Number of columns $\left(\mathrm{N}_{\mathrm{C}}\right)$ & $1-5$ \\
\hline
\end{tabular}




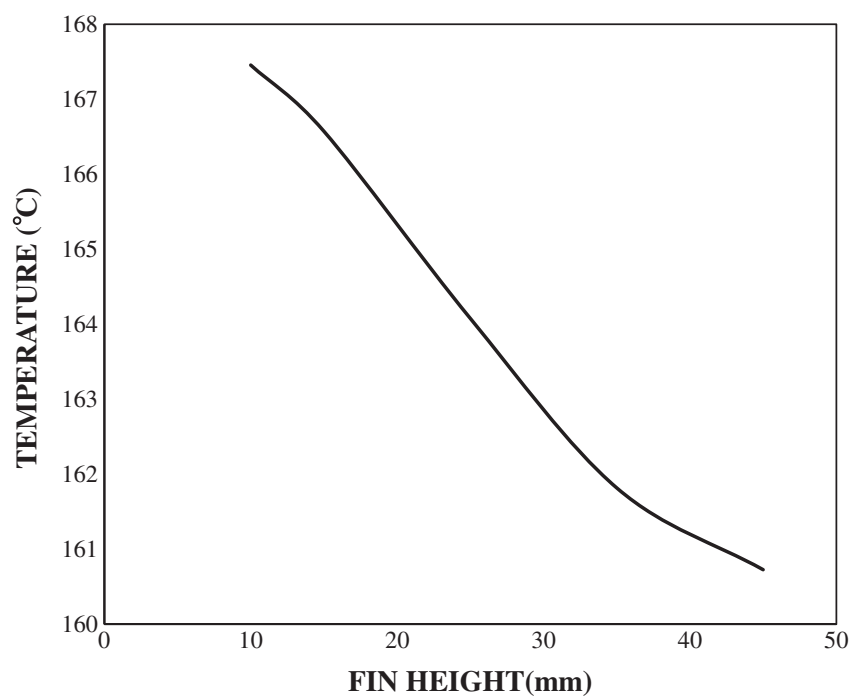

Figure 7. Variation of base plate temperature with height of the fin $\left(R_{O}=15 \mathrm{~mm}, R_{I}=9 \mathrm{~mm}, N=1\right)$

by decrease in base plate temperature is attributed to increase in convection. As the height of fin is increased, the exposed solid surface to the fluid increased, allowing the fluid to carry more amount of heat. The hot air moves up as a result of density difference resulting in augmented convection.

3.1b Case 2 - Variation with outer radius: Figure 8 shows the variation in heat transfer with increase in outer radius of the cylindrical pin fin. The other parameters are kept constant to study the dependence of outer radius alone. There is a $5^{\circ} \mathrm{C}$ decrease in base plate temperature when outer radius is $15 \mathrm{~mm}$ compared to that of a fin of $2 \mathrm{~mm}$ outer radius. This is because of increase in contact area of the fin with the base plate with increase in radius of the fin. The increase in contact area increases the heat transfer due to conduction at the tip of the fin leading to a decreased base plate temperature.

3.1c Case 3 - Variation with inner radius: Analysis is done on the hollow cylindrical pin fins by varying the inner radius of the fin. With increase in inner radius of the hollow fin, the volume of solid portion of the fin decreases leading to phenomenal reduction in weight when compared to solid cylindrical pin fins. In terms of heat and fluid flow, it is observed that the increase in hollow space with increase in inner radius causes an increased air movement over the cylindrical wall of the fin. As a result, increased volume of air that enters the hollow space of the fin augments the heat transfer. The flow of fluid is similar to that of flow inside a cylindrical cavity. The increased air movement causes a decrease in base plate temperature with increase in radius. However, the increase in inner radius of the cylindrical pin fin decreases the contact area of the solid fin with the base plate. This leads to a decrease in conduction mode of heat transfer. Thus it can be seen that the heat transfer characteristic of the fin depends on the combined effect of decrease in conduction and increase in convection mode of heat transfer. This leads to presence of an optimal value of inner radius to have an augmented heat transfer. The optimal value of inner 


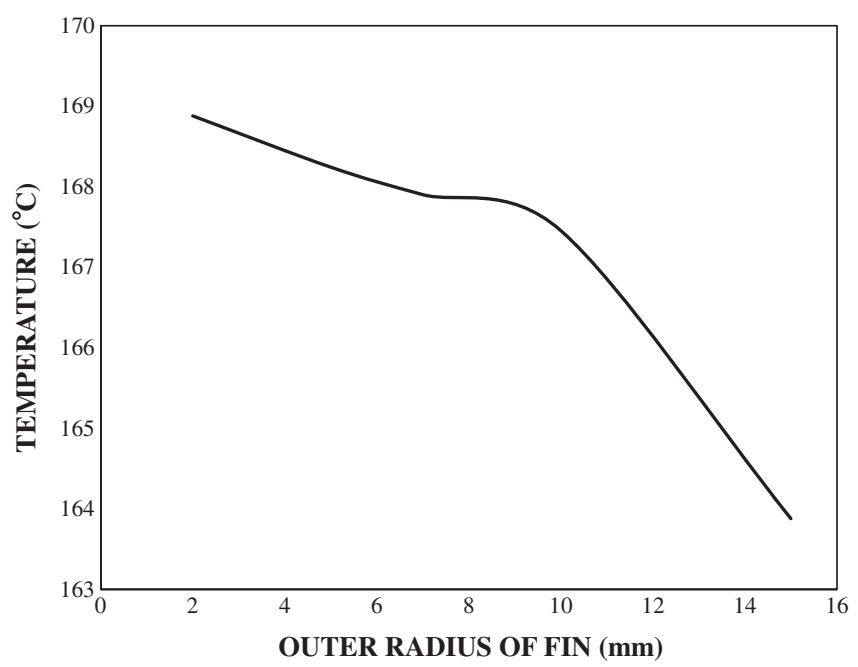

Figure 8. Variation of base plate temperature with Outer Radius of fin $\left(H=10 \mathrm{~mm}, \mathrm{~N}=1, \mathrm{R}_{\mathrm{I}}=1 \mathrm{~mm}\right)$.

radius is found to be around $5 \mathrm{~mm}$ for a fin height of $45 \mathrm{~mm}$ and outer radius of $10 \mathrm{~mm}$ supplied with a heat flux of $100 \mathrm{~W}$ as shown in figure 9. Moreover, the decrease in base plate temperature is found to be higher for $200 \mathrm{~W}$ heat supply when compared to $100 \mathrm{~W}$ heat supply for the same parameters. Figure 10 represents the radial variation of hollow fin for different inner radius (6, 9, 12 and $14 \mathrm{~mm}$ ) keeping the outer radius, height and heat duty as constant as $15 \mathrm{~mm}, 45 \mathrm{~mm}$ and $100 \mathrm{~W}$. The range is fixed between the ambient temperature $20^{\circ} \mathrm{C}$ and the maximum temperature $156^{\circ} \mathrm{C}$. It is clear from the figure that increase in hollow cavity increases more air inside the fin and the temperature gradient increases proportionally.

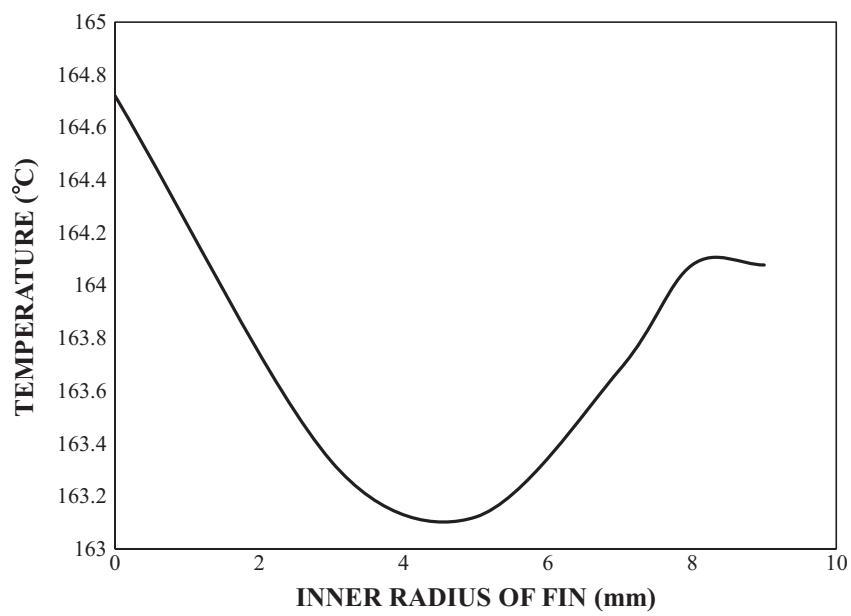

Figure 9. Variation of base plate temperature with inner radius of fin $\left(\mathrm{H}=45 \mathrm{~mm}, \mathrm{~N}=1, \mathrm{R}_{\mathrm{O}}=10 \mathrm{~mm}\right.$, $\mathrm{Q}=100 \mathrm{~W})$. 


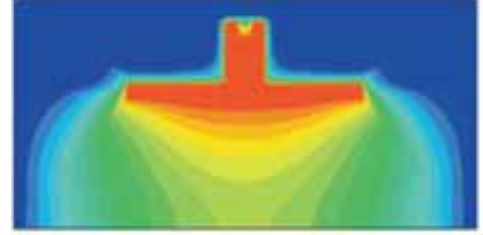

(a)

For $R_{i}=6 \mathrm{~mm}$

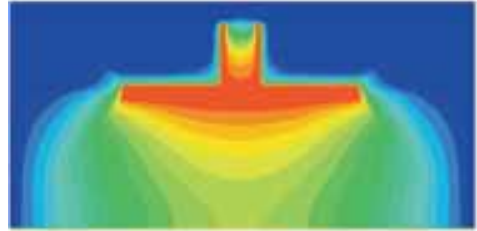

(c) For $\mathrm{R}_{\mathrm{i}}=12 \mathrm{~mm}$

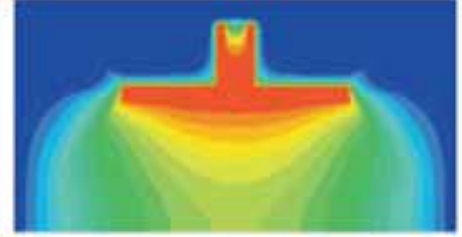

(b) For $R_{i}=9 \mathrm{~mm}$

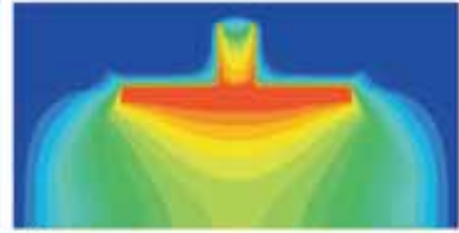

(d) For $R_{\mathrm{i}}=14 \mathrm{~mm}$
Temperature [C]

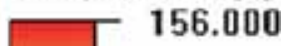

139.000

122.000

105.000

88.0000

71.0000

54.0000

37.0000

20.0000

Figure 10. Radial variation of fin temperature for different inner radius $\left(H=45 \mathrm{~mm}, \mathrm{~N}=1, \mathrm{R}_{\mathrm{O}}=15\right.$ $\mathrm{mm}, \mathrm{Q}=100 \mathrm{~W}$ ).

3.1d Case 4 - Variation in number of rows and number of columns: Analysis has been done by varying the number of rows and number of columns keeping other parameters constant. Rows refer to the number of fins along the width base plate and column refers to the number of fins along the column of the base plate. It is clear from figure 11 that as the number of rows are increased, the base temperature kept on decreasing. As the number of fins increase, there is an increase in both the contact area and the exposed area of the fin. This leads to increase in convection and conduction mode of heat transfer. Figure 12 shows the variation in base plate temperature with the increase in number of columns. As the number of fins on the base plate increases, the contact area of the fin increases and more heat transfer occurs. At the same time

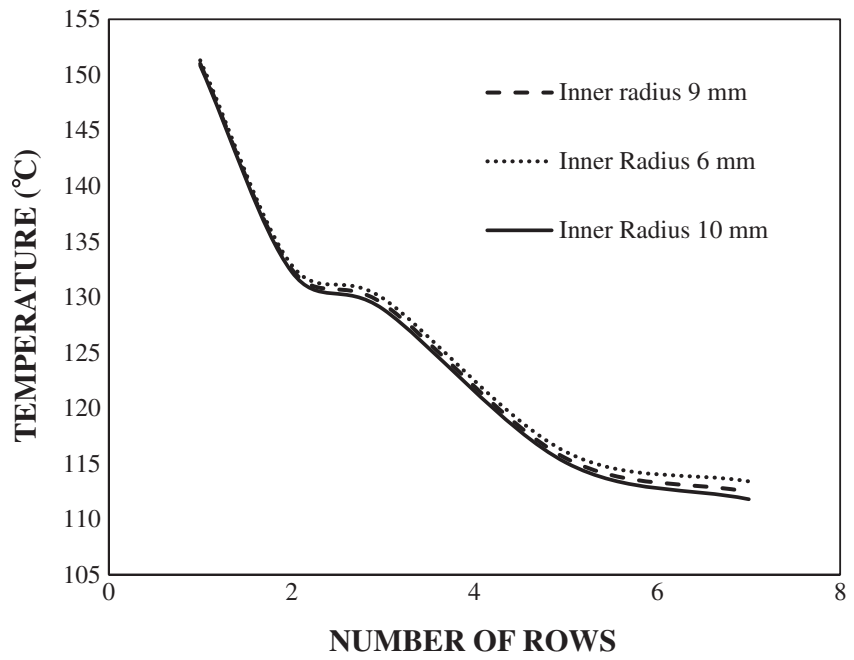

Figure 11. Variation of base plate temperature with Number of rows of Fin $\left(N_{C}=5, H=45 \mathrm{~mm}, \mathrm{R}_{\mathrm{O}}=\right.$ $15 \mathrm{~mm})$. 


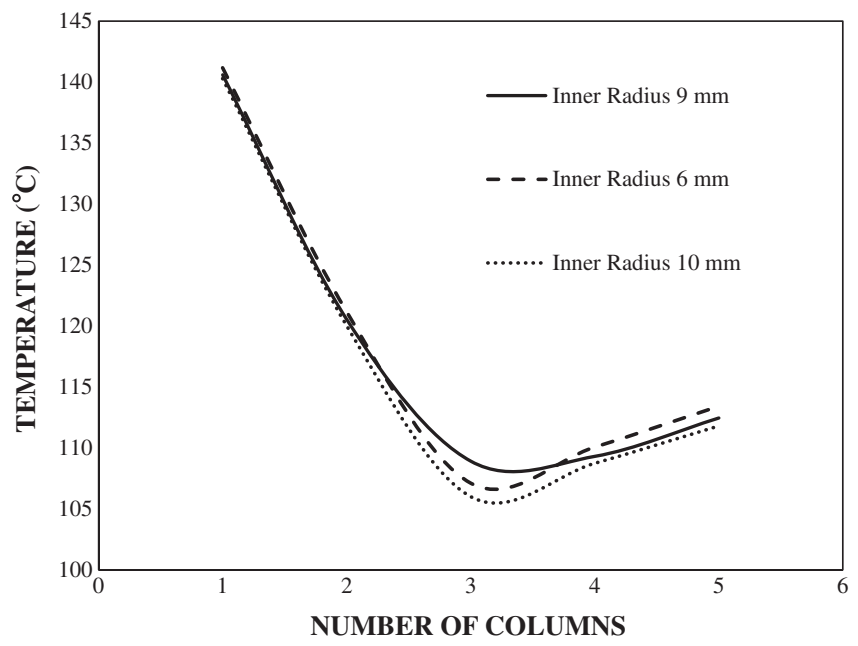

Figure 12. Variation of base plate temperature with number of columns of fin $\left(\mathrm{N}_{\mathrm{R}}=7, \mathrm{H}=45 \mathrm{~mm}\right.$, $\left.\mathrm{R}_{\mathrm{O}}=15 \mathrm{~mm}\right)$.

the air movement should not be restricted by clogged arrangement of the fins which results in inefficient heat transfer. The reason is attributed to the decrease in the amount of fin spacing. If the fin spacing is very less, the effect of boundary layer plays an important role. If the thickness of the boundary layer is greater than the fin spacing, there is a decrease in air movement of the fin. It can be observed from figure 12 that base plate temperature reduces up to certain value with the increase in number of fins. When the number of columns of fins increases beyond 3 there is an increase in base plate temperature. This shows the existence of an optimal number of fin columns in the range of values analysed.

\subsection{Comparison of hollow and solid fin - weight reduction}

It can be seen from the analysis that the hollow cylindrical pin fins provide a method for enhanced heat transfer rate compared to a solid cylindrical pin fin. This is because of increase in the air movement through the hollow space of the fin leading to an increase in convection. Thus the hollow cylindrical pin fins can effectively replace solid pin fins of the same radius and height providing a decreased base plate temperature. Moreover, hollow fins provide an additional advantage when compared to solid fins. The hollow fin has less volume compared to that of a solid fin. The decrease in volume of the fin leads to a decrease in weight of the fin which is essential in many electronic and aerospace cooling applications. Decrease in weight of the fin also demands less amount of material leading to decrease in cost involved in the use of heat sink. The percentage weight reduction can be calculated from relation

$$
\begin{aligned}
& \% \text { weight reduction of the fin } \\
& =\frac{\text { (weight of the solid fin) }-(\text { weight of the hollow fin })}{(\text { weight of solid fin })} * 100 \text {. }
\end{aligned}
$$

Volume of solid fin and hollow fin are calculated from Eqs. 4 and 5 and weight of the fin is calculated from Eq. (6).

$$
\text { Volume of solid fin }=\pi R_{o}^{2} H
$$




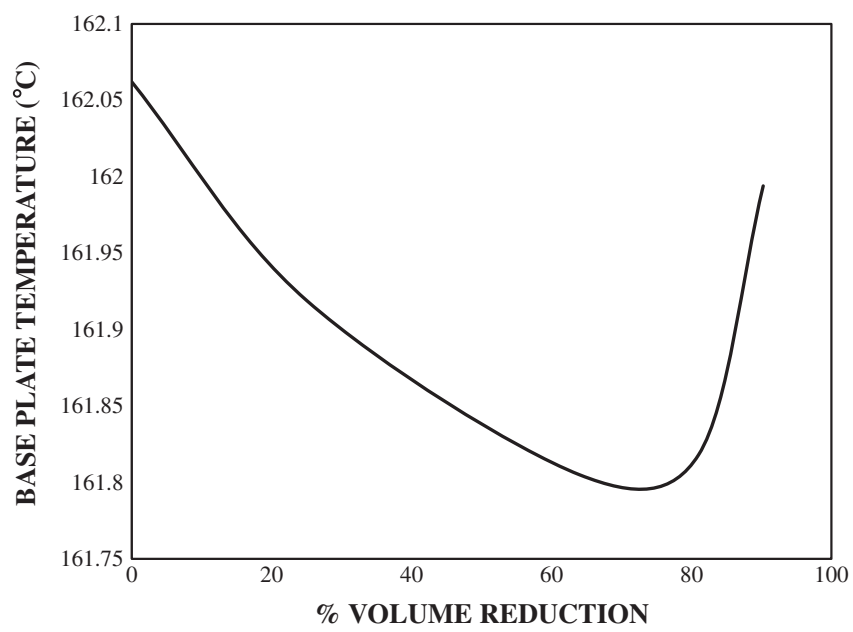

Figure 13. Weight reduction $\left(\mathrm{N}=1, \mathrm{H}=35 \mathrm{~mm}, \mathrm{R}_{\mathrm{O}}=10 \mathrm{~mm}\right)$.

$$
\begin{aligned}
\text { Volume of Hollow fin }(V) & =\pi\left(R_{o}^{2}-R_{i}^{2}\right) H \\
\text { Weight of the fin } & =\rho g V,
\end{aligned}
$$

where $\mathrm{V}$ is the volume of the fin. It is evident from figure 13 that a maximum of $90.25 \%$ weight reduction is achieved compared to solid fin for same base plate temperature and $70 \%$ is achieved with decreased temperature for a single fin arrangement.

\subsection{Comparison of hollow fin and solid fin-temperature, velocity profiles}

A comparison is made between solid and hollow pin fin in terms of base plate temperature and velocity contour for a fin height of $45 \mathrm{~mm}$, outer and inner radius 15 and $14 \mathrm{~mm}$ for a single fin. Figures 14 and 15 represent the temperature contour of solid and hollow pin fin. There is a reduction in base plate temperature for hollow fin when compared to the solid cylindrical pin fin. Though the temperature reduction is very less, hollow fin has a very less volume compared to the solid fin. In this case there is a weight reduction of $87.11 \%$. In case of array of fins (7 rows and 5 columns) for a $45 \mathrm{~mm}$ fin, $\mathrm{R}_{0}=15 \mathrm{~mm}, \mathrm{R}_{\mathrm{i}}=14 \mathrm{~mm}$, the difference in base plate temperature for $200 \mathrm{~W}$ is around $5^{\circ} \mathrm{C}$ with same weight reduction.
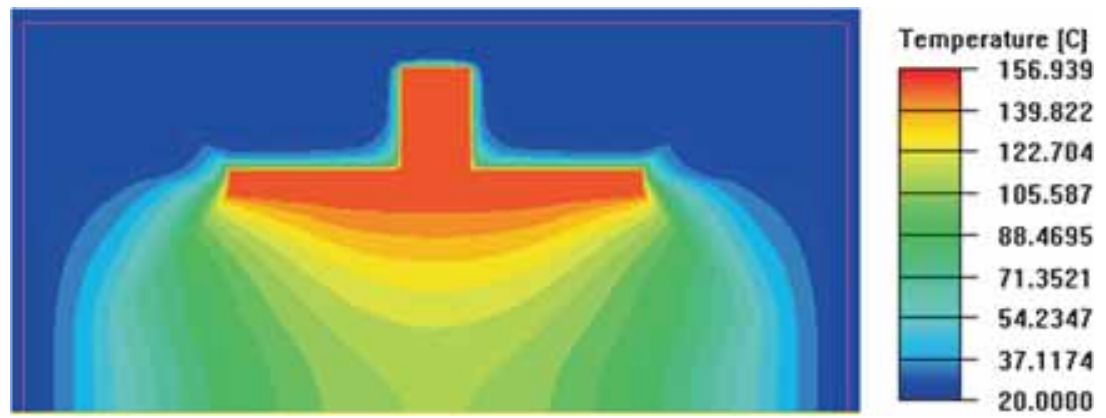

Figure 14. Temperature Line Contour of solid fin $\left(H=45 \mathrm{~mm}, \mathrm{~N}=1, \mathrm{R}_{\mathrm{o}}=15 \mathrm{~mm}, \mathrm{R}_{\mathrm{i}}=14 \mathrm{~mm}\right)$. 

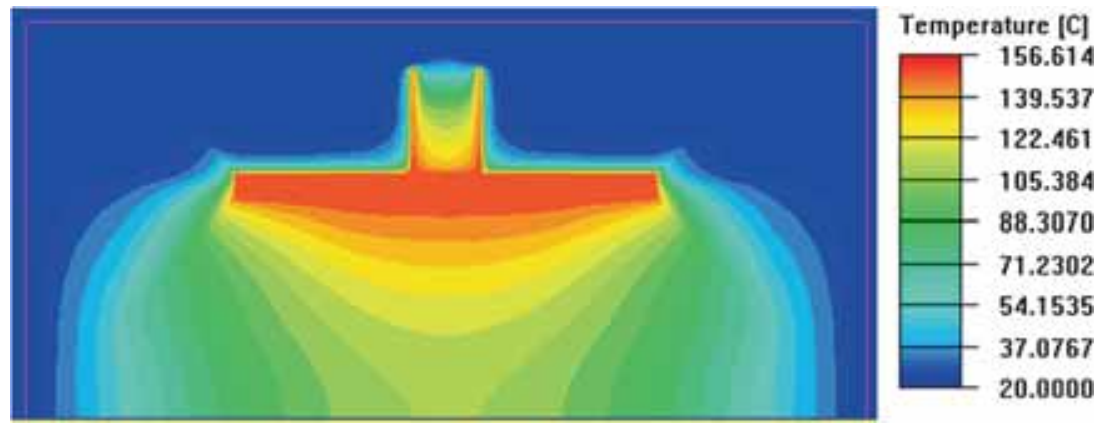

Figure 15. Temperature line contour of hollow fin $\left(H=45 \mathrm{~mm}, \mathrm{~N}=1, \mathrm{R}_{\mathrm{o}}=15 \mathrm{~mm}, \mathrm{R}_{\mathrm{i}}=14 \mathrm{~mm}\right)$.
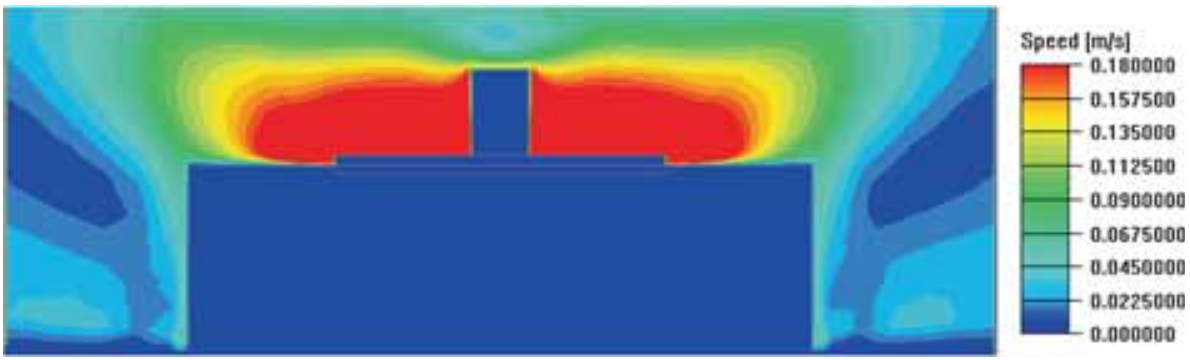

Figure 16. Velocity contour of solid fin $\left(H=45 \mathrm{~mm}, N=1, R_{0}=15 \mathrm{~mm}, R_{i}=14 \mathrm{~mm}\right)$.
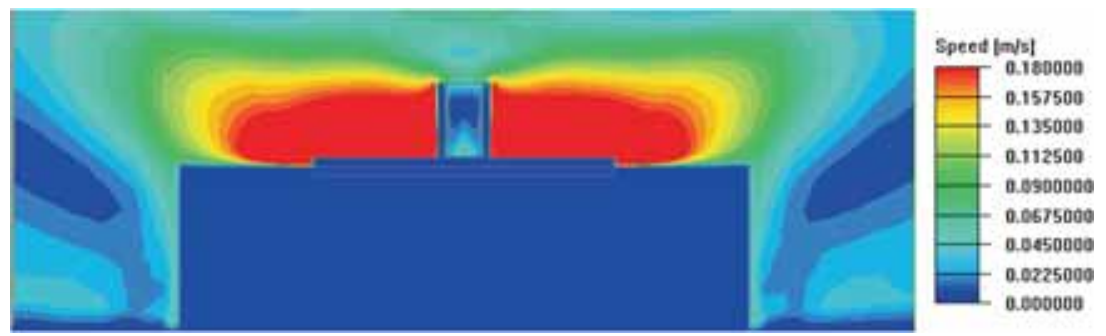

Figure 17. Velocity contour of hollow fin $\left(H=45 \mathrm{~mm}, \mathrm{~N}=1, \mathrm{R}_{\mathrm{o}}=15 \mathrm{~mm}, \mathrm{R}_{\mathrm{i}}=14 \mathrm{~mm}\right)$.

The high temperature region is represented by red colour which is the base plate temperature and from base plate the temperature varies to the top of the fin. This temperature gradient is responsible for the fluid movement over the fin resulting in increased heat transfer. The reason for augmented heat transfer is the result of convective heat transfer in the inside surface of the hollow fin. Figures 16 and 17 compares the velocity contour of solid and hollow pin fin. In a solid pin fin the convective heat transfer occurs only on the outer surface of the fin. But in a hollow pin fin due to the cylindrical cavity there is an augmented convective heat transfer inside the fin due to air movement inside the cavity because of the temperature gradient on inner surface of the fin along its height which is clear from the cut section of a hollow fin from figure 17. The inner cavity of the hollow fin has a maximum fluid velocity of $0.045 \mathrm{~m} / \mathrm{s}$ compared to the solid as represented in figures 16 and 17. The air movement inside the fin cavity is due to the buoyancy effect. Figure 18 represents the comparison of solid and hollow cylindrical pin fins in terms of base plate temperature for same outer radius and inner radius of the hollow fins varied for a fin 


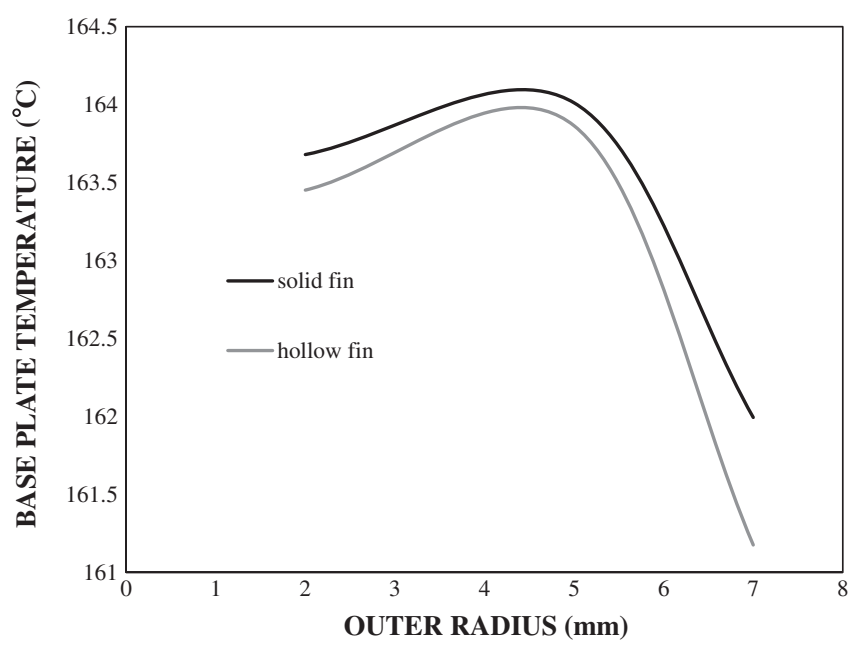

Figure 18. Comparison of solid and hollow pin fins $(\mathrm{Q}=100 \mathrm{~W}, \mathrm{H}=25 \mathrm{~mm}, \mathrm{~N}=1)$.

height of $25 \mathrm{~mm}$ and heat flux of $100 \mathrm{~W}$ for a single fin. It is evident that the hollow fins have enhanced heat transfer compared to solid fins.

\subsection{Optimization}

It can be noticed from the analysis in section 3.1, that there exists an optimal value of inner radius and number of columns of fins. Optimization involves simultaneous searching of the combination of all the parameters to obtain the minimal base plate temperature. Hence a combination of ANN-GA is used to obtain the optimal parameters for decrease in base plate temperature. ANN provides a prediction of base plate temperature for the given input such as height, inner and outer radius, heat duty, number of rows and columns of fins and GA is applied on the trained neural network to obtain the optimal parameters with minimal effort.

3.4a Artificial neural network: Artificial neural Network comprises of interconnected neurons which are the essential building block of a neural network. A group of neurons form a layer. The layers are classified as input, output and hidden layers. Every neuron is assigned a weight and an activation function. The input information is propagated by the feed forward perception network and the output error is back propagated to adjust the weight. The process of obtaining the appropriate weight is called training of the neural network. ANN is applied to results obtained from the simulation to predict the base plate temperature for different set of fin parameters, since performing the numerical analysis for all the parameters is time consuming. In the present work, genetic algorithm is applied on the trained neural network to find the optimum fin parameters for augmented heat transfer. Hence ANN is used for prediction purpose alone and genetic algorithm is used for optimization based on the prediction of ANN.

In the present work, results of 400 numerical simulations are used to test and validate the neural network. The Genetic algorithm is further applied on the Neural Network to obtain the optimal parameters of heat transfer to obtain the minimum base plate temperature. The neural network is designed using MATLAB Neural network toolbox. $80 \%$ of the obtained result of the numerical simulation is used to train the network and the remaining $20 \%$ of the results 


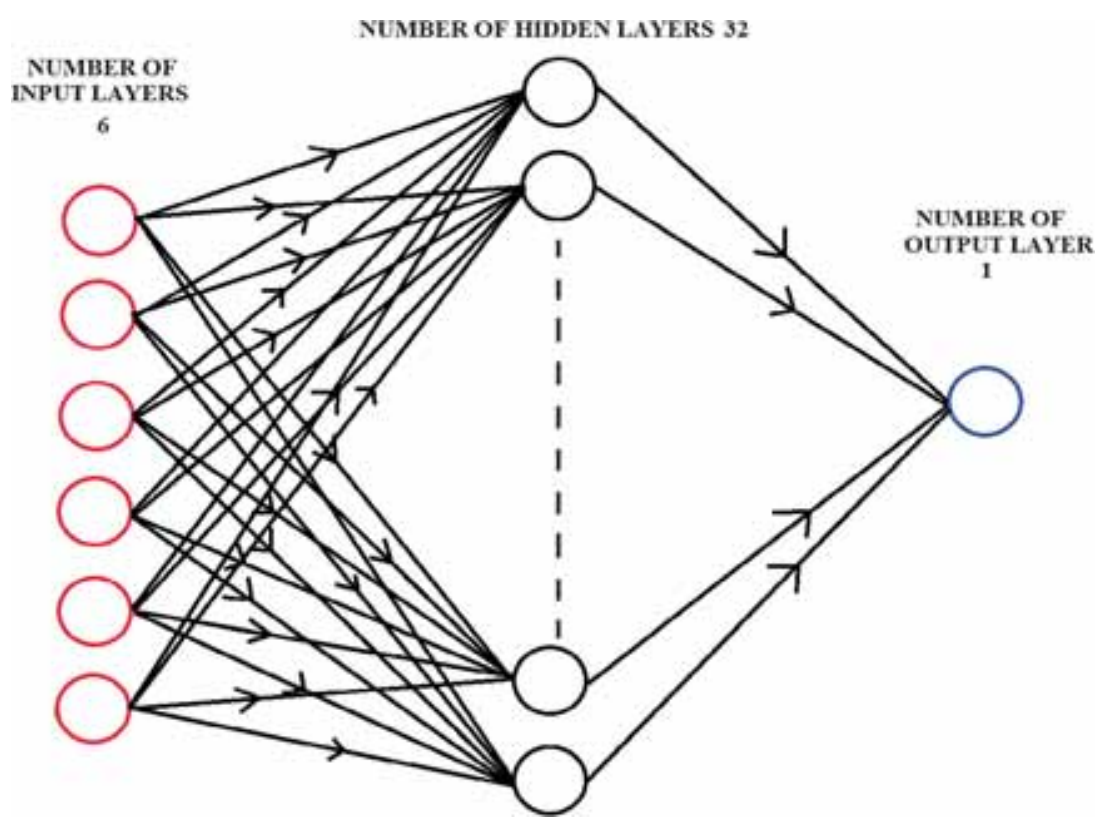

Figure 19. Neural network comprising of different layers.

are used for the purpose of testing and validation. Since the number of input parameters varied is 6 , the number of neurons in the input layer is 6 as shown in figure 19. Sigmoid transfer function is used as the activation function for the hidden layer and is represented in Eq. (7). A linear transfer function is used for the output layer. The majority of the computations have been carried out by the hidden layers. So Sigmoid transfer function is used for the hidden layer. However, the output layer does not perform much computation, so a linear transfer function will reduce the computation time. A single hidden layer is found to be able to predict the base plate temperature within the limit of allowable error. Levenberg - Marquardt [Demuth \& Beale (1992)] back propagation algorithm is used to train the network. Initially the number of hidden layer is taken to be 10. The number of hidden layer is then increased and the neural network is retrained to reduce the mean standard error (to approach zero) and increase the regression coefficient (to approach 1). The designed ANN is shown in figure 19. The optimal number of hidden layers is found to be 32 to have the required mean standard error.

$$
S(t)=\frac{1}{1+e^{-t}}
$$

The neural network gave a mean squared error of 0.01 and the mean regression coefficient to be 0.98. The regression plot for the training, testing, and validation data is shown in figure 20. It can be concluded that the neural network is able to predict the base plate temperature for varying input parameters. Table 3 represents the prediction of the base plate temperature for the given input data by taking three examples.

3.4b Genetic Algorithm and Optimization of Fin parameters: Genetic Algorithm is a soft computing based optimization technique based on natural selection during evolution of living 
Training: $\mathbf{R}=0.98515$

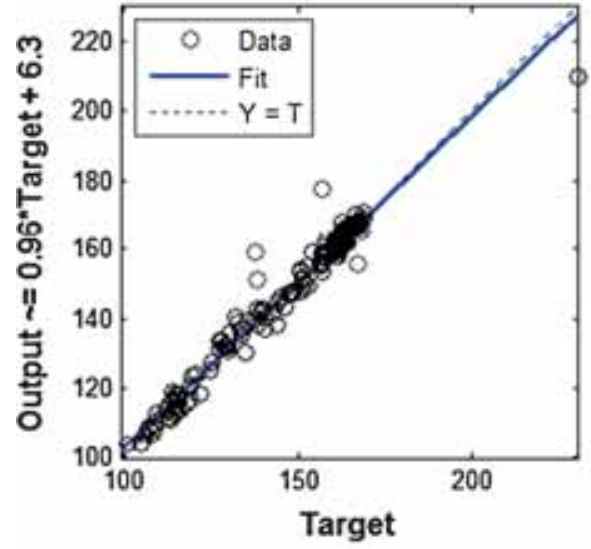

Test: $\mathbf{R}=\mathbf{0 . 9 6 7 8 7}$

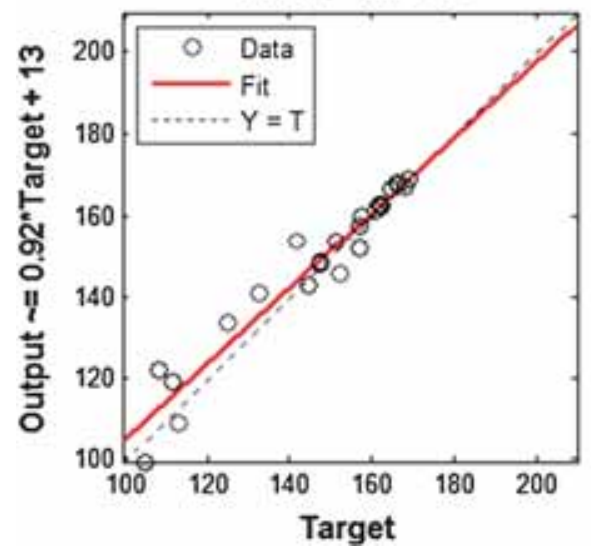

Validation: $\mathbf{R}=0.96213$

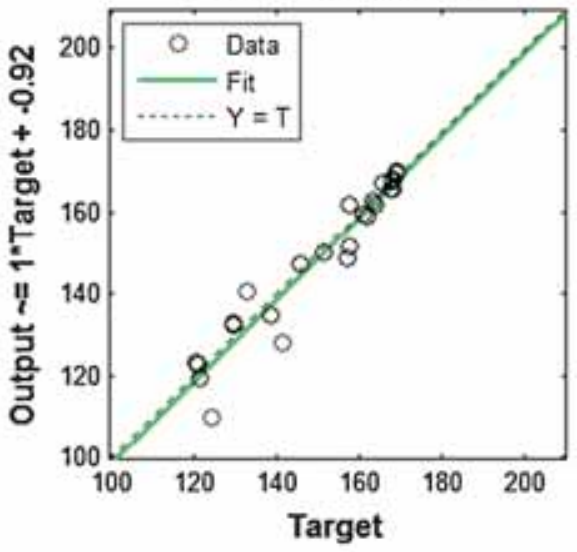

All: $\mathrm{R}=0.98103$

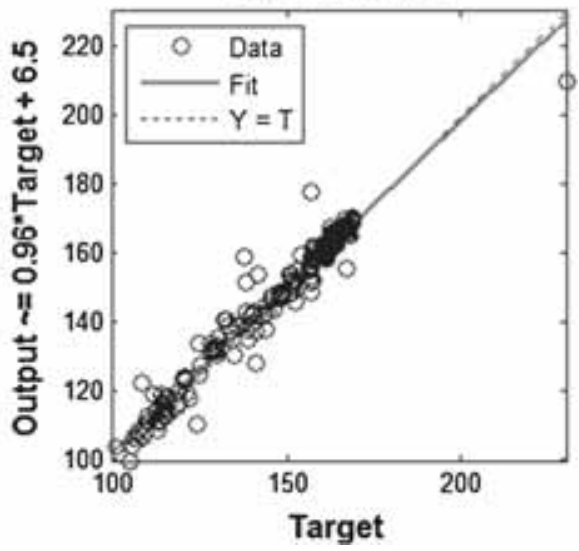

Figure 20. Regression plot.

Table 3. Neural network prediction.

\begin{tabular}{lccccccc}
\hline $\begin{array}{l}\text { Heat } \\
\text { flux } \\
(\mathrm{W})\end{array}$ & $\begin{array}{c}\text { Height } \\
\text { of the } \\
\text { fin }(\mathrm{H}) \\
(\mathrm{mm})\end{array}$ & $\begin{array}{c}\text { Outer } \\
\text { radius } \\
\left(\mathrm{R}_{\mathrm{O}}\right) \\
(\mathrm{mm})\end{array}$ & $\begin{array}{c}\text { Inner } \\
\text { radius } \\
\left(\mathrm{R}_{\mathrm{I}}\right) \\
(\mathrm{mm})\end{array}$ & $\begin{array}{c}\text { Number } \\
\text { of rows } \\
\left(\mathrm{N}_{\mathrm{R}}\right)\end{array}$ & $\begin{array}{c}\text { Number } \\
\text { of } \\
\text { columns } \\
\left(\mathrm{N}_{\mathrm{C}}\right)\end{array}$ & $\begin{array}{c}\text { Base plate } \\
\text { temperature }\left({ }^{\circ} \mathrm{C}\right) \\
\text { Numerical } \\
\text { result }\end{array}$ & $\begin{array}{c}\text { Base plate } \\
\text { temperature }\left({ }^{\circ} \mathrm{C}\right) \\
\text { Neural } \\
\text { network }\end{array}$ \\
\hline 20 & 25 & 5 & 4.7 & 1 & 1 & 117.14 & 116.85 \\
200 & 45 & 15 & 14 & 7 & 5 & 188.45 & 188.32 \\
100 & 45 & 15 & 14 & 5 & 2 & 124.77 & 124.70 \\
\hline
\end{tabular}

organisms. In the present work, the objective is to minimize the base plate temperature. The upper limit height and the outer radius are taken to be 45 and $15 \mathrm{~mm}$, respectively. The base plate temperature is subjected to the constraints depending on the geometry of the base plate. The maximum number of fins along the row depends on the parameters like width of the base plate and outer radius of the fin. Similarly, the maximum number of fins along the column depends on 
Table 4. Optimal fin geometry.

\begin{tabular}{lccccc}
\hline $\begin{array}{l}\text { Heat } \\
\text { flux }(\mathrm{W})\end{array}$ & $\begin{array}{c}\text { Height } \\
\text { of the fin }(\mathrm{H}) \\
(\mathrm{mm})\end{array}$ & $\begin{array}{c}\text { Outer } \\
\text { radius }\left(\mathrm{R}_{\mathrm{O}}\right) \\
(\mathrm{mm})\end{array}$ & $\begin{array}{c}\text { Inner } \\
\text { radius }\left(\mathrm{R}_{\mathrm{I}}\right) \\
(\mathrm{mm})\end{array}$ & $\begin{array}{c}\text { Number of } \\
\text { rows }\left(\mathrm{N}_{\mathrm{R}}\right)\end{array}$ & $\begin{array}{c}\text { Number of } \\
\text { columns }\left(\mathrm{N}_{\mathrm{C}}\right)\end{array}$ \\
\hline 20 & 45 & 15 & 9.28 & 5 & 3 \\
60 & 45 & 15 & 9.32 & 5 & 3 \\
100 & 45 & 15 & 9.35 & 5 & 3 \\
250 & 45 & 15 & 9.58 & 5 & 3 \\
500 & 45 & 15 & 9.72 & 5 & 3 \\
\hline
\end{tabular}

the parameters like length of the base plate and outer radius of the fin. Similarly, the maximum number of fins along the column is the ratio of the length of the base plate and the outer radius of the fin. The inner radius of the fin is subjected to the constraint that it is always less than the outer radius of the fin. The parameters for GA are obtained by performing a thorough parametric study by varying one parameter and keeping all other parameters constant. Probability of mutation $=0.006$; Population size $=30$; maximum number of generations $=30$. Crossover probability $=0.5$. Stochastic uniform is used for parent selection and fitness based replacement is used for survivor selection. Initial population of the genetic algorithm is taken to be random values satisfying the constraints. The combination of parameters to determine the minimum fitness function is determined by evaluating the parameters in the present and successive generation. This is carried out using the genetic algorithm global optimization toolbox in MATLAB. Genetic algorithm is directly applied on the results of the neural network, the objective function is neural network itself. The optimal fin parameters for enhanced heat transfer obtained in the present case is shown in table 4 .

\section{Conclusion}

In the present work, numerical study of natural convection heat transfer in a hollow cylindrical pin fin was carried out using commercial CFD code ANSYS FLUENTC). Fin parameters such as inner and outer radius of the fin, fin height, number of rows and columns of the fin were varied and corresponding heat transfer characteristics were studied. It is clear from the results that hollow cylindrical pin fin results in an increase in heat transfer with a substantial reduction in weight of about $90 \%$. ANN is used to predict the heat transfer with a regression coefficient of 0.98 . Genetic algorithm was employed on the neural network to optimize the fin geometry for enhanced heat transfer.

\section{Nomenclature}

$\mathrm{H} \quad$ Fin height, mm

$\mathrm{N} \quad$ Number of fins

$R_{O} \quad$ Outer radius of fin, $m m$

$\mathrm{R}_{\mathrm{i}} \quad$ Inner radius of fin, $\mathrm{mm}$

$\mathrm{N}_{\mathrm{R}} \quad$ Number of rows

$\mathrm{N}_{\mathrm{C}} \quad$ Number of columns 
Q Power supplied to heater base plate, W

$\mathrm{t} \quad$ Base plate thickness, mm

$\mathrm{h}$ Convection heat transfer coefficient, $\mathrm{W} /\left(\mathrm{m}^{2} \mathrm{~K}\right)$

$\mathrm{T}_{\mathrm{a}} \quad$ Ambient temperature, ${ }^{\circ} \mathrm{C}$

$\mathrm{T}$ Temperature, ${ }^{\circ} \mathrm{C}$

$\Delta \mathrm{T} \quad$ Base-to-ambient temperature difference, ${ }^{\circ} \mathrm{C}$

$\mathrm{k}$ Thermal conductivity, $\mathrm{W} /(\mathrm{m} \mathrm{K})$

g Gravitational acceleration, $\mathrm{m} / \mathrm{s}^{2}$

$\mu \quad$ Dynamic viscosity, $\mathrm{N} \mathrm{s} / \mathrm{m}^{2}$

$\beta \quad$ Volumetric thermal expansion coefficient, $1 / \mathrm{K}$

$v \quad$ Kinematic viscosity, $\mathrm{m}^{2} / \mathrm{s}$

$\alpha \quad$ Thermal diffusivity, $\mathrm{m}^{2} / \mathrm{s}$

$\rho \quad$ Density of fin material, $\mathrm{kg} / \mathrm{m}^{3}$

$\mathrm{c}_{\mathrm{p}} \quad$ Specific heat capacity at constant pressure, $\mathrm{J} / \mathrm{kg} \mathrm{K}$

\section{References}

Bejan A and Dan N 1999 Constructal trees of convective fins. J. Heat Transf. 121(3): 675-682

Cavazzuti M and Corticelli M A 2008 Optimization of heat exchanger enhanced surfaces through multiobjective Genetic Algorithms. Numer. Heat Transfer, Part A: Appl. 54(6): 603-624

Demuth H and Beale M 1992 MATLAB: Neural Network Toolbox: User's Guide. Math Works

Haldar S C 2010 Natural convection about a cylindrical pin element on a horizontal plate. Int. J. Thermal Sci. 49(10): 1977-1983

Harahap F and McManus H N 1967 Natural convection heat transfer from horizontal rectangular fin arrays. J. Heat Transf. 89(1): 32-38

Jones C D and Smith L F 1970 Optimum arrangement of rectangular fins on horizontal surfaces for freeconvection heat transfer. J. Heat Transf. 92(1): 6-10

Karvinen R and Karvinen T 2010 Optimum geometry of fixed volume plate fin for maximizing heat transfer. Int. J. Heat Mass Transf. 53(23): 5380-5385

Khaled A R 2010 Investigation of heat transfer enhancement through permeable fins. J. Heat Transf. 132(3): 034503

Ledezma G and Bejan A 1996 Heat sinks with sloped plate fins in natural and forced convection. Int. J. Heat Mass Transf. 39(9): 1773-1783

Liu F B 2005 A fuzzy approach to the convective longitudinal fin array esign. Int. J. Thermal Sci. 44(3): 211-217

Rao R V and Patel V 2013 Multi-objective optimization of heat exchangers using a modified teachinglearning-based optimization algorithm. Appl. Mathemat. Model. 37(3): 1147-1162

Sasikumar M and Balaji C 2002 Optimization of convective fin systems: a holistic approach. Heat Mass Transfer 39(1): 57-68

Seyf H R and Layeghi M 2010 Numerical analysis of convective heat transfer from an elliptic pin fin heat sink with and without metal foam insert. J. Heat. Trans-T ASME 132(7): 071401-071401-9

Sharqawy M H and Zubair S M 2007 Efficiency and optimization of an annular fin with combined heat and mass transfer-an analytical solution. Int. J. Refrig. 30(5): 751-757

Siw S C, Shih T I P, Alvin M A and Chyu M K 2012 Effects of pin detached space on heat transfer and pin-fin arrays. J. Heat Transf. 134(8): 081902

Sparrow E M and Charmchi M 1980 Laminar heat transfer in an externally finned circular tube. J. Heat Transf. 102(4): 605-611

Sparrow E M and Lee L 1975 Effects of fin base-temperature depression in a multifin array. J. Heat Transf. 97(3): 463-465 
Starner K E and McManus H N 1963 An experimental investigation of free-convection heat transfer from rectangular-fin arrays. J. Heat Transf. 85(3): 273-277

Tsai J T, Liu T K and Chou J H 2004 Hybrid Taguchi-genetic algorithm for global numerical optimization. IEEE Trans. Evol. Comput. 8(4): 365-377

Yang D K, Lee K S and Song S 2006 Fin spacing optimization of a fin-tube heat exchanger under frosting conditions. Int. J. Heat Mass Transf. 49(15): 2619-2625

Yazicioglu B 2005 Performance of rectangular fins on a vertical base in free convection heat transfer. MS thesis, Middle East Technical University, Ankara

Yazicioglu B and Yuncu H 2007 Optimum fin spacing of rectangular fins on a vertical base in free convection heat transfer. Heat Mass Transf. 44(11-21): 1

Yuncu H and Anbar G 1998 An experimental investigation on performance of rectangular fins on a horizontal base in free convection heat transfer. Heat Mass Transf. 33(5-6): 507-514 